\title{
KAMPANYE MEDIA KAMPUS SEHAT SEBAGAI INISIASI HEALTH PROMOTING UNIVERSITY DI FKKMK UGM
}

\author{
Rina Tri Agustini ${ }^{1}$, Aulia Zahro Novitasari ${ }^{2}$, Dwi Rahmawaty3, Nurhijrianti Akib ${ }^{4}$ \\ 1,2,3,4 Universitas Gadjah Mada \\ E-mail: rinatriagustini.rta@gmail.com
}

\begin{abstract}
ABSTRAK
Tujuan dari studi ini yaitu melihat gambaran dari kesadaran terhadap kampanye media SALAM Sehat, penilaian konten media SALAM Sehat, evaluasi formatif dan evaluasi proses dalam pelaksanaan kampanye media SALAM Sehat sebagai inisiasi dari Health Promoting University (HPU) di Fakultas Kedokteran, Kesehatan Masyarakat, dan Keperawatan Universitas Gadjah Mada (FKKMK UGM). Kampanye ini berfokus pada konsumsi buah dan sayur setiap hari, aktivitas fisik secara rutin, dan menjaga kesehatan mental yang dilakukan dari Bulan Juni - Oktober di mana 'SALAM' merupakan singkatan dari SAntap buah dan sayur setiap hari, LAkukan aktivitas fisik secara rutin, and Menjaga kesehatan mental. Metode yang digunakan dalam studi ini yaitu desain post test melalui cross sectional online survey untuk evaluasi kuantitatif dan menggunakan desain studi kasus melalui Focus Group Discussion untuk evaluasi kualitatif. Hasil studi ini yaitu kampanye telah dilakukan melalui penyebaran media online dan pemasangan media cetak yang dalam prosesnya bekerjasama dengan organisasi mahasiswa yang ada di FKKMK serta melibatkan partisipasi civitas akademika lainnya seperti Dekan FKKMK, Wakil Dekan FKKMK, dan Penanggung Jawab HPU UGM. Penyebaran media online berupa poster dan filler melalui akun dan grup organisasi. Pemasangan media cetak berupa Traffic Light Food Labelling di kantin, banner motivasi jalan kaki di kantong parkir, poster motivasi aktivitas fisik di tangga, dan stiker motivasi menggunakan tangga di lift. Sebagian besar responden memiliki kesadaran terhadap Kampanye Media SALAM Sehat. Pesan media SALAM Sehat dinilai telah memenuhi ketentuan elemen pesan. Kampanye ini membutuhkan pengembangan pesan yang konsisten, terintegrasi dengan kebijakan, pengadaan lingkungan, serta kerjasama yang lebih luas. Kampanye ini dinilai inovatif dengan melibatkan kerjasama antarorganisasi mahasiswa, namun terdapat kendala berupa koordinasi internal yang bergantung pada budaya organisasi.
\end{abstract}

Kata Kunci: Kampanye; Kampus Sehat; HPU; Media; SALAM Sehat.

\begin{abstract}
The purpose of this study is to see an overview of awareness of the SALAM Sehat media campaign, assessment of SALAM Sehat media content, formative evaluation and process evaluation in implementing the SALAM Sehat media campaign as an initiation from Health Promoting University (HPU) in the Faculty of Medicine, Public Health and Nursing. Gadjah Mada University (FKKMK UGM). This campaign focuses on consumption of fruits and vegetables every day, regular physical activity, and maintaining mental health which is carried out from June to October where 'SALAM' stands for Savor fruits and vegetables every day, Do regular physical activity, and Maintain mental health. The method used in this study is post test design through cross sectional online survey for quantitative evaluation and using case study design through Focus Group Discussion for qualitative evaluation. The result of this study is that the campaign has been carried out through the distribution of online media and the installation of print media which in the process collaborates with student organizations in FKKMK and involves the participation of other academics such as the FKKMK Dean, FKKMK Deputy Dean, and the UGM HPU Person in Charge. Dissemination of online media
\end{abstract}


in the form of posters and fillers through organizational accounts and groups. Installation of printed media in the form of Traffic Light Food Labeling in the canteen, motivational walking banners in parking bags, motivational posters for physical activity on stairs, and motivation stickers using stairs in elevators. Most of the respondents have awareness of the SALAM Sehat Media Campaign. SALAM Sehat media message is considered to have fulfilled the message element requirements. This campaign requires the development of messages that are consistent, integrated with policies, environmental procurement, and wider cooperation. This campaign is considered innovative by involving collaboration between student organizations, but there are obstacles in the form of internal coordination that depends on organizational culture.

Keywords: Campaign; Healthy Campus; HPU; Media; GREETINGS Healthy.

\section{PENDAHULUAN}

Menurut World Health Organization (2017) data kematian akibat Penyakit Tidak Menular (PTM) di Indonesia mencapai 73\% atau sebanyak 1.340 .000 kematian. Diet yang tidak sehat dan kurang aktivitas fisik merupakan faktor resiko terjadinya penyakit obesitas, hipertensi dan peningkatan kolesterol yang akan mengarah pada kematian di seluruh dunia akibat penyakit tidak menular. Selain itu, WHO (2017) menyebutkan bahwa terjadi pergeseran angka kejadian penyakit tidak menular, di mana penduduk usia muda cenderung mulai terkena penyakit jantung, hipertensi, diabetes dan kolesterol. Hal ini didukung dengan data global yang menunjukkan bahwa lebih dari $80 \%$ dewasa muda di seluruh penjuru dunia tidak aktif melakukan aktivitas fisik (WHO, 2012). Berdasarkan data Sirkesnas Kementerian Kesehatan Republik Indonesia (2016) diperoleh data prevalensi penduduk usia $\geq 18$ tahun yang memiliki tekanan darah tinggi sebesar 32,4 persen dan obesitas sebesar 20,7 persen.

Sebagian besar dewasa muda seperti mahasiswa, staff, dan dosen cenderung banyak menghabiskan waktunya di universitas sehingga terdapat banyak ancaman kesehatan bagi kelompok dewasa muda di universitas antara lain yaitu asma, obesitas, diabetes, kekerasan, kecelakaan, kehamilan yang tidak diinginkan, dan penyakit menular (Fertman \& Allensworth, 2010). Mehri, et al. (2016) menyebutkan bahwa promosi hidup sehat di kalangan mahasiswa tergolong rendah di mana mereka cenderung tidak memerhatikan asupan makanan dan jarang melakukan aktivitas fisik, sehingga diperlukan upaya promosi kesehatan di kalangan mahasiswa yang bertujuan untuk membantu mereka menerapkan gaya hidup sehat.

Program promosi kesehatan universitas merupakan sebuah program promosi kesehatan yang dilaksanakan di Universitas dengan sasaran program yaitu mahasiswa, staff, dosen dan masyarakat sekitar universitas yang bertujuan untuk meningkatkan kesehatan mahasiswa, karyawan universitas dan komunitas luas (Fertman \& Allensworth, 2010). Asian University Network-Health Promotion Network (AUN-HPN) yang di dalamnya terdapat Universitas Gadjah Mada, merumuskan kerangka konsep Health Promoting University (HPU) untuk menuju universitas sehat (Healthy University). Berdasarkan kerangka konsep yang telah disusun terdapat tujuh strategi promosi kesehatan yang diterapkan di universitas yaitu implementasi program literasi kesehatan, kesehatan mental dan manajemen stres, keterikatan dan stimulasi sosial, aktivitas fisik dan mobilitas aktif, meningkatkan pola makan sehat dan gizi seimbang, pendidikan kesehatan reproduksi dan perilaku, serta kesehatan tempat kerja (AUN-HPN, 2017).

Fakultas Kedokteran, Kesehatan Masyarakat dan Keperawatan Universitas Gadjah Mada telah menerapkan salah satu strategi promosi kesehatan di universitas yaitu dengan 
mendeklarasikan Kawasan Tanpa Rokok (KTR) pada tahun 2004 dan menjadi rujukan dalam penerapan kebijakan kampus bebas rokok di UGM. Berdasarkan hasil penelitian yang dilakukan oleh Soh (2015) dengan adanya penerapan kawasan tanpa rokok di Fakultas Kedokteran UGM terbukti menurunkan presentase perilaku merokok dari 4,8\% pada tahun 2003 menjadi 3,2\% pada tahun 2007, serta meningkatkan pengetahuan tentang bahaya merokok di kalangan mahasiswa FK UGM. Selain itu, pada dies natalis FKKMK UGM yang ke-72, FKKMK UGM menyatakan bahwa akan menjadikan Fakultas sebagai penggerak HPU yang didukung dengan pelaksanaan deklarasi HPU pada tanggal 3 September 2018.

Berdasarkan hasil analisis komunitas yang telah dilakukan di FKKMK UGM melalui survei didapatkan sebanyak 178 responden yang terdiri dari mahasiswa S1, S2, pendidikan spesialis, S3, tenaga kependidikan, dan staf pengajar/dosen didapatkan data aktivitas fisik yang kurang di mana sebagian besar responden mengaku tidak melakukan aktivitas fisik minimal 30 menit per hari selama 7 hari terakhir dan sebanyak 30,3\% responden menghabiskan lebih dari 8 jam sehari untuk melakukan kegiatan sambil duduk. Data terkait konsumsi buah dan sayur juga menunjukkan perilaku konsumsi buah dan sayur yang masih rendah di mana sebanyak $(37,6 \%)$ responden hanya mengonsumsi buah sebanyak satu kali sehari selama 30 hari terakhir dan sebanyak $(37,1 \%)$ responden mengonsumsi sayur hanya satu kali dalam sehari selama 30 hari terakhir, serta terdapat $12,9 \%$ responden yang memiliki kolesterol tinggi. Kemudian data terkait kesehatan mental juga menunjukkan bahwa selama 12 bulan terakhir $(5,2 \%)$ responden mengaku memiliki keinginan untuk bunuh diri, $(3,9 \%)$ pernah membuat rencana untuk bunuh diri, serta $(2,8 \%)$ responden pernah mencoba untuk bunuh diri.

Oleh karena itu, diperlukan strategi promosi kesehatan yang dapat membantu meningkatkan kesadaran civitas akademika FKKMK UGM dalam menerapkan konsumsi buah dan sayur, beraktivitas fisik, dan memanfaatkan layanan kesehatan mental. Salah satu strategi promosi kesehatan yang dapat digunakan yaitu melalui kampanye media di mana kampanye merupakan tindakan yang didasari oleh prinsip persuasi, yaitu mengajak dan mendorong khalayak untuk menerima atau melakukan sesuatu yang dianjurkan (Ramadhan, 2017). Kampanye media dilakukan dengan menggunakan media online melalui internet dan pemasangan media cetak di lingkungan kampus di mana poster merupakan salah satu strategi pemasaran sosial yang dapat mendistribusikan pesan dan popular di kampus (Matter \& Neighbors, 2004 dalam Potter dkk., 2009).

Kampanye media SALAM (SAntap buah dan sayur setiap hari, LAkukan aktivitas fisik secara rutin, and Menjaga kesehatan mental) Sehat inisiasi HPU dalam upaya peningkatan kesadaran civitas akademika FKKMK UGM terhadap konsumsi buah dan sayur, melakukan aktivitas fisik, dan menjaga kesehatan mental telah dilakukan di FKKMK UGM sejak Bulan Juni hingga Oktober. Sehingga, perlu diketahui gambaran kesadaran terhadap Kampanye Media SALAM Sehat, penilaian konten media "SALAM Sehat", evaluasi formatif dan evaluasi proses dalam program Kampanye Media SALAM Sehat.

Landasan teori yang digunakan dalam evaluasi ini yaitu teori hirarki efek kampanye media yang menjelaskan bahwa setiap kampanye pada awalnya menyampaikan pesan untuk memengaruhi kesadaran dan pemahaman tentang tema kampanye, isi pesan kampanye, slogan kampanye, dan persepsi dari penerima pesan bahwa pesan yang disampaikan sesuai dengan kondisinya. Kesadaran dari pesan tersebut merupakan tahap awal yang nantinya akan berubah menjadi respon terhadap kampanye, di mana orang yang sudah memiliki kesadaran akan rentan terhadap tahap perubahan yang lebih lanjut. Tingkat perubahan selanjutnya adalah proses kognitif dan afektif seperti pengetahuan tentang pesan kesehatan yang disampaikan, rekomendasi kesehatan, sikap dan keyakinan tentang pesan kesehatan serta keyakinan, self-efficacy dan niat untuk melakukan perubahan. Kemudian, 
tahap perubahan yang paling akhir adalah terjadinya perubahan perilaku di mana adanya percobaan untuk melakukan isi pesan, adopsi dan pemeliharaan perilaku seperti berkurangnya perilaku yang tidak sehat, peningkatan akses terhadap sarana yang menunjang kesehatan dan lain-lain (Bauman, Smith, Maibach, \& Reger-Nash, 2006).

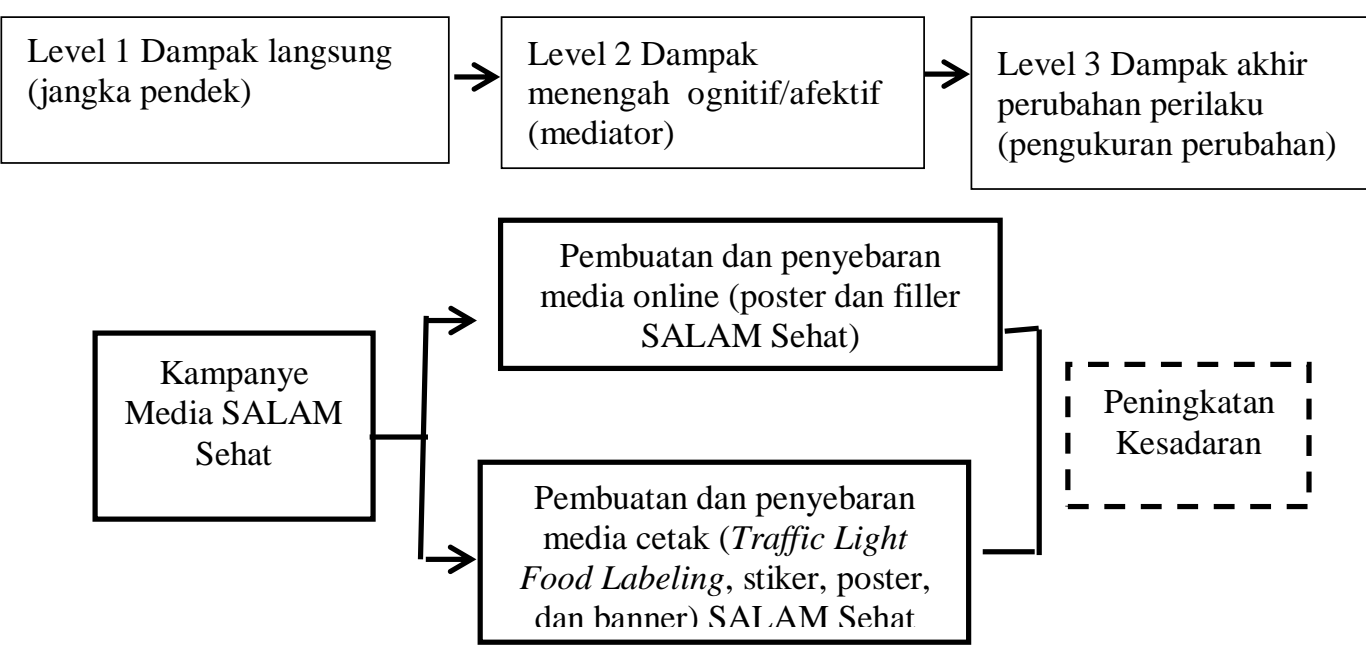

Gambar 1. Kerangka Konsep Kampanye Media SALAM Sehat

\section{METODOLOGI}

\section{Lokasi dan populasi}

Penelitian yang bertujuan untuk mengevaluasi program Kampanye Media SALAM Sehat ini berlokasi di lingkungan Fakultas Kedokteran, Kesehatan Masyarakat, dan Keperawatan UGM (FKKMK UGM). Populasi dalam penelitian ini yaitu seluruh civitas akademika FKKMK UGM meliputi mahasiswa S1, S2, S3, tenaga kependidikan, dan dosen / staf pengajar.

\section{Rancangan Penelitian Kuantitatif}

Penelitian ini merupakan evaluasi program dengan menggunakan desain post-test (Witte, Meyer, \& Martell, 2001 dalam Potter dkk., 2009) untuk menilai kesadaran civitas akademika FKKMK terhadap keberadaan Kampanye Media SALAM Sehat dan penilaian terhadap konten media SALAM Sehat secara kuantitatif. Rancangan survei ini dipilih untuk menilai jangkauan penyebaran dan persepsi civitas akademika terhadap media kampanye SALAM Sehat (Creswell, 2016). Metode survei yang digunakan yaitu online survey (Nesbary, 2000; Sue \& Ritter, 2007 dalam Cresswell, 2016) karena segmentasi sasaran yang cukup luas, sehingga lebih efisien dan cepat dalam pengumpulan data di era internet saat ini. Survei ini merupakan cross-sectional survey karena mengumpulkan data satu per satu dalam satu waktu. Analisis data kuantitatif yang digunakan yaitu dengan menampilkan tabel yang berisi angka-angka dan persentase-persentase yang mendeskripsikan responden (Creswell, 2016).

Berikut komponen yang diidentifikasi dalam survei: 
1) Karakteristik responden, meliputi usia, jenis kelamin, dan status civitas akademika FKKMK.

2) Kesadaran terhadap kampanye media SALAM Sehat, meliputi keterpaparan, frekuensi paparan, paparan pesan, dan sumber paparan yang mengampanyekan SALAM Sehat (Panduwinata \& Lumintang, 2008).

3) Konten media kampanye media SALAM Sehat, meliputi courtesy (kesesuaian isi dengan penerima pesan), concreteness (ketepatan isi pesan dengan topik), completeness (kelengkapan isi pesan), correctness (kebenaran dan keakuratan isi pesan), conciseness (keringkasan isi pesan), clarity (kemudahan untuk dipahami), dan consideration (sesuai dengan situasi dan kondisi) (Cutlip, Center \& Broom dalam Stellarosa \& Kurniasari, 2009).

Sampel dalam penelitian kuantitatif ini dipilih menggunakan convenience sampling yakni dengan memilih responden berdasarkan kemudahan dan ketersediaan dalam pengambilan data (Creswell, 2016). Link dari online survey disebarkan kepada civitas akademika melalui email dan grup whatsapp selama tiga hari.

\section{Rancangan Penelitian Kualitatif}

Desain penelitian kualitatif ini menggunakan studi kasus yang sering digunakan dalam evaluasi (Creswell, 2016) untuk menganalisis program kampanye media SALAM Sehat secara mendalam (Stake, 1995; Yin, 2009, 2012 dalam Creswell, 2016). Evaluasi formatif untuk menilai kelebihan dan kekurangan material dan strategi kampanye sebelum dan selama implementasi kampanye media SALAM Sehat. Sedangkan, evaluasi proses untuk mengukur usaha dan keluaran langsung dari kampanye media SALAM Sehat termasuk melihat proses dalam implementasi program (Coffman, 2002).

Pengambilan data dilakukan melalui Focus Group Discussion (FGD) untuk mendapatkan pemahaman kelompok. Selain itu, informasi yang didapatkan banyak dalam waktu yang relatif singkat (Cresswell, 2016). Instrumen pengambilan data menggunakan panduan FGD berisi (Coffman, 2002):

1) Evaluasi formatif, meliputi kelebihan dan kekurangan serta saran dan masukan untuk keberlanjutan program kampanye media SALAM Sehat.

2) Evaluasi proses, meliputi persepsi tentang HPU persepsi tentang kampanye media SALAM Sehat, persepsi tentang kaitan antara HPU dengan kampanye media SALAM Sehat, kesesuaian media dengan sasaran, media terbaik secara keseluruhan, pengorganisasian organisasi mahasiswa yang terlibat, penyebaran media, hambatan dan pendukung dalam kampanye media SALAM Sehat.

Analisis data dilakukan secara bertahap mulai dari mengorganisasikan informasi, membaca informasi secara keseluruhan dan memberi kode, membuat uraian terperinci terkait kasus dan konteksnya, menetapkan pola dan mencari hubungan antarkategori, menginterpretasikan hasil, serta menyajikan infromasi dalam bentuk matriks dan narasi (Saryono \& Anggraeni, 2011). Peer debriefing dengan melakukan diskusi bersama rekan peneliti untuk mendapatkan interpretasi lain dalam menjaga keabsahan data (Cresswell, 2016). Informan dipilih menggunakan quota sampling (Saryono \& Anggraeni, 2011) yaitu kelompok pertama terdiri dari enam orang perwakilan organisasi mahasiswa yang terlibat dalam kampanye media SALAM Sehat (kode infroman: A1 sampai A6) dan kelompok kedua yaitu enam orang perwakilan mahasiswa di luar organisasi mahasiswa yang terlibat (kode informan: B1 sampai B6). 


\section{HASIL}

Dalam pelaksanaan Kampanye Media SALAM Sehat dilakukan koordinasi dan kerjasama dengan organisasi mahasiswa yang ada di FKKMK UGM serta membentuk "TIM HPU FKKMK". Pembuatan dan penyebaran media online dan cetak dilakukan sesuai dengan Standard Operational Procedure yang disepakati bersama Badan Eksekutif Mahasiswa Keluarga Mahasiswa (BEM KM) FKKMK yang bertugas membuat konten dan desain media aktivitas fisik, Himpunan Mahasiswa Gizi Kesehatan (HIMAGIKA) yang bertugas membuat konten dan desain media konsumsi buah dan sayur, Himpunan Mahasiswa Keperawatan (HIMIKA) yang bertugas membuat konten dan desain media kesehatan mental, serta Ikatan Mahasiswa Pascasarjana Ilmu Kesehatan Masyarakat (IMP IKM) dan Himpunan Mahasiswa Pascasarjana Keperawatan (HMPK). Seluruh organisasi mahasiswa bertugas memaksimalkan penyebaran seluruh media.

Pembuatan dan penyebaran media cetak juga melibatkan civitas akademika FKKMK dalam pembuatan konten, desain, dan model (talent) dalam media, serta pemasangan di lingkungan FKKMK. Media cetak yang telah diterapkan yaitu Traffic Light Food Labeling (TLFL) yang dipasang di beberapa kantin, banner motivasi dan foto perwakilan organisasi tentang berjalan kaki yang dipasang di kantong parkir, poster motivasi dan foto Dekan FKKMK, Wakil Dekan FKKMK, dan penanggung jawab HPU terkait aktivitas fisik yang dipasang di tangga, dan stiker motivasi menggunakan tangga yang dipasang di depan lift.

\section{Hasil Evaluasi Kuantitatif}

Karakteristik responden dalam penelitian ini berdasarkan responden civitas akademika FKKMK UGM yang mengisi survei dari 13 sampai 16 September 2018, sejumlah 111 responden. Distribusi frekuensi karakteristik responden dapat dilihat pada tabel 1 .

Tabel 1. Distribusi frekuensi karakteristik demografi responden

\begin{tabular}{lcc}
\hline \multicolumn{1}{c}{ Karakteristik } & $\boldsymbol{N}$ & \% \\
\hline Usia & & \\
$18-22$ & 25 & 22.5 \\
$23-27$ & 58 & 52.3 \\
$28-32$ & 9 & 8.1 \\
$33-37$ & 12 & 10.8 \\
$38-42$ & 6 & 5.4 \\
$43-47$ & 1 & 0.9 \\
Jenis Kelamin & & \\
Laki-laki & 28 & 25.2 \\
Perempuan & 83 & 74.8 \\
Status & & \\
Mahasiswa S1 & 22 & 19.8 \\
Mahasiswa S2 & 83 & 74.8 \\
Mahasiswa S3 & 4 & 3.6 \\
Dosen/Staf Pengajar & 2 & 1.8 \\
Jumlah & $\mathbf{1 1 1}$ & $\mathbf{1 0 0}$ \\
\hline Sumber: Data Primer, September 2018
\end{tabular}

Sumber: Data Primer, September 2018

Tabel 1 menunjukan karakteristik demografi responden meliputi usia mayoritas antara 23-27 tahun, mayoritas berjenis kelamin perempuan, dan mayoritas status civitas akademika yaitu mahasiswa S2 FKKMK UGM. 


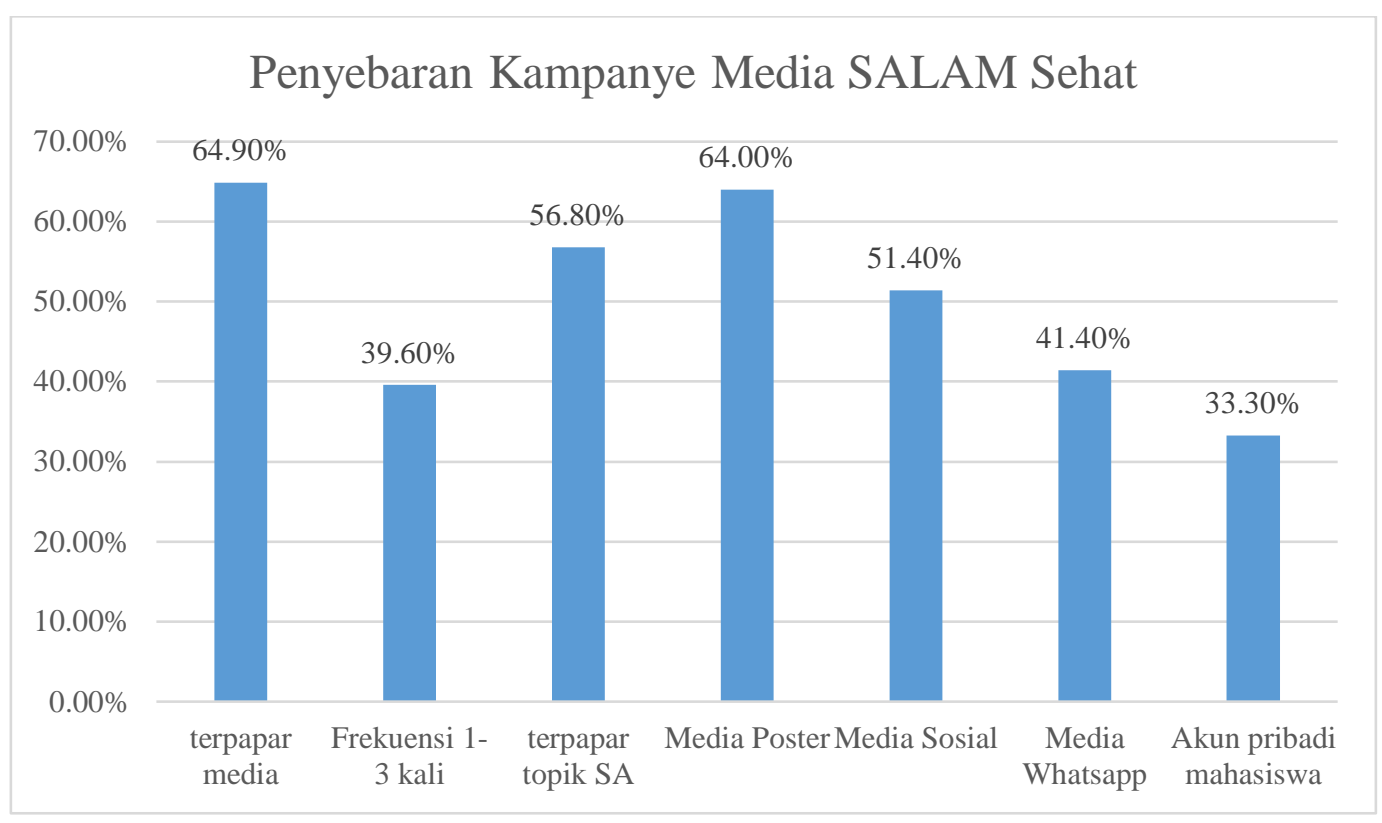

Sumber: Data Primer, September 2018

Gambar 2. Gambaran Kesadaran Sasaran terhadap Kampanye Media SALAM Sehat

Mayoritas responden pernah melihat atau mendengar kampanye media SALAM Sehat dengan frekuensi terbanyak sebanyak 1-3 kali. Kemudian, mayoritas responden pernah melihat atau mendengar kampanye media SALAM Sehat tentang santap buah dan sayur setiap hari, disusul dengan lakukan aktivitas fisik dan menjaga kesehatan mental, di mana bentuk paparan media terbanyak adalah poster. Distribusi sumber informasi kampanye media SALAM sehat yang paling banyak melalui media sosial, di mana sumber media sosial yang terbanyak melalui Whatsapp, dan sumber akun sumber informasi terbanyak dari akun pribadi mahasiswa.

Tabel 2 Distribusi pesan kampanye media SALAM Sehat yang paling diingat

\begin{tabular}{ll}
\hline Pesan kampanye & $\boldsymbol{N}$ \\
\hline Peregangan sejenak & 8 \\
Menjaga kesehatan mental & 58 \\
Cobalah bicara & 7 \\
Konsumsi buah dan sayur & 88 \\
Lakukan aktivitas fisik & 28 \\
\hline
\end{tabular}

Sumber: Data Primer, September 2018

Tabel 2 menunjukkan bahwa pesan dari kampanye media SALAM Sehat yang paling diingat oleh responden adalah pesan terkait konsumsi buah dan sayur. 


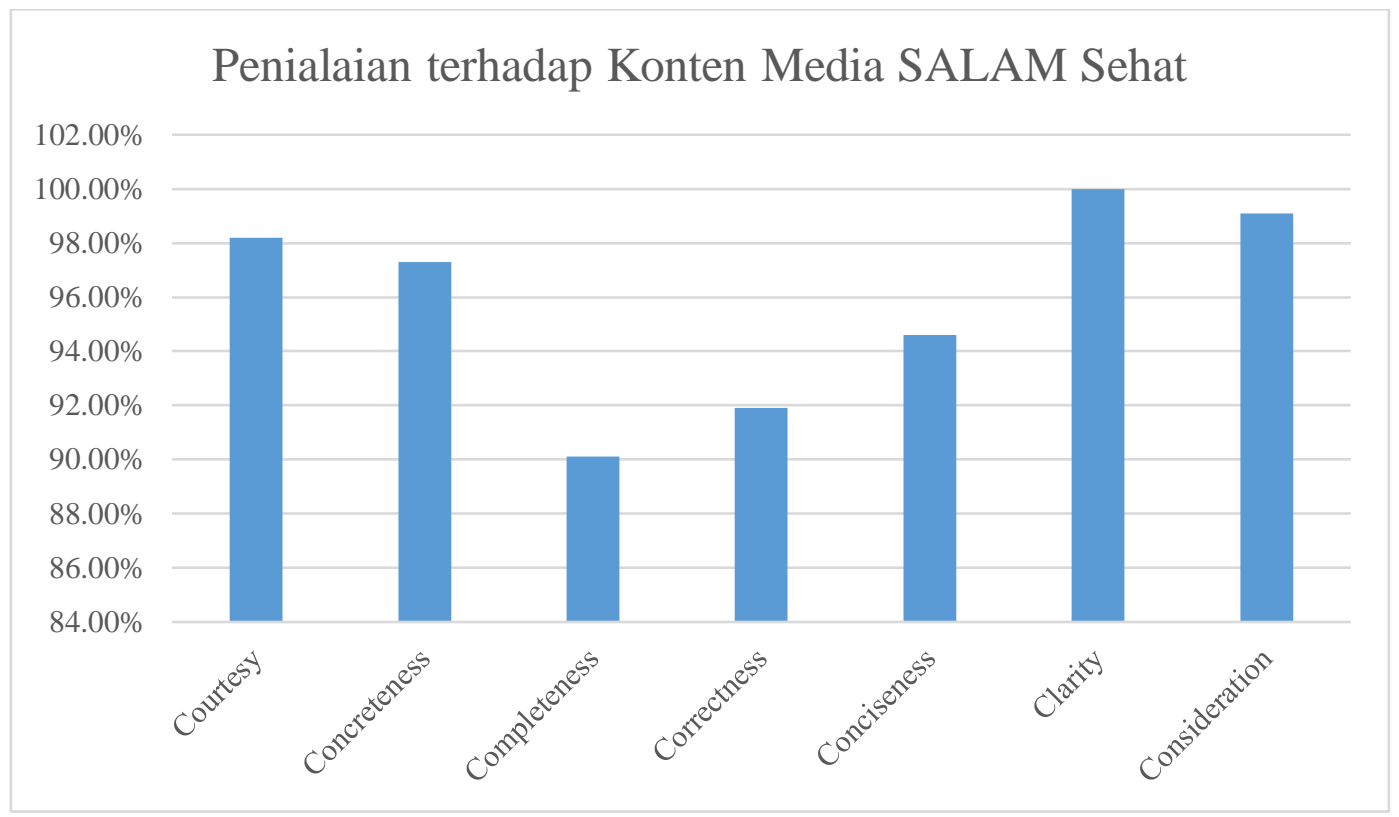

Sumber: Data Primer, September 2018

Gambar 3. Penilaian Sasaran terhadap Konten Media SALAM Sehat

Kesesuaian isi pesan dengan minat responden civitas akademika FKKMK UGM memiliki sebaran yang hampir merata di setiap media SALAM Sehat yang telah disebarkan. Media yang dianggap paling sesuai adalah poster nomor 7 tentang jenis dan manfaat aktivitas fisik, serta poster nomor 8 tentang tips dan trik melakukan aktivitas fisik.

Kesesuaian pesan dengan topik pesan kampanye media SALAM Sehat di FKKMK UGM di mana menurut mayoritas responden isi pesan sudah sesuai dengan topik pesan kampanye media SALAM Sehat yang telah disebarkan. Media yang dianggap paling sesuai dengan topik SALAM Sehat adalah poster nomor 1 tentang penjelasan SALAM sehat.

Kelengkapan informasi pendukung pada pesan yang ada di poster media SALAM Sehat di FKKMK UGM di mana menurut mayoritas responden pesan sudah memiliki informasi pendukung yang lengkap. Media yang dianggap memiliki informasi pendukung paling lengkap adalah poster nomor 7 tentang jenis dan manfaat aktivitas fisik, serta poster nomor 8 tentang tips dan trik melakukan aktivitas fisik.

Penilaian keakuratan dan kebenaran sumber pesan di mana menurut mayoritas responden media SALAM Sehat memiliki sumber terpercaya. Media yang dianggap memiliki sumber paling terpercaya adalah poster nomor 3 tentang penjelasan porsi konsumsi buah dan sayur.

Pesan media SALAM Sehat menurut mayoritas responden sudah memiliki pesan yang ringkas dan jelas. Media yang dianggap memiliki pesan yang ringkas dan jelas adalah poster nomor 1 tentang penjelasan dari tiga perilaku sehat dalam SALAM Sehat dan poster nomor 3 penjelasan porsi konsumsi buah dan sayur.

Penilaian terhadap kemudahan dalam memahami pesan media SALAM sehat di mana menurut seluruh responden media SALAM Sehat mudah dipahami. Media yang dianggap memiliki pesan yang paling mudah dipahami adalah poster nomor 1 tentang penjelasan dari SALAM Sehat.

Penilaian terhadap kesesuaian isi pesan poster media SALAM sehat dengan situasi dan kondisi di mana menurut mayoritas responden media SALAM Sehat sudah sesuai dengan 
situasi dan kondisi. Media yang dianggap memiliki pesan yang paling sesuai dengan situasi dan kondisi adalah poster nomor 8 tentang tips dan trik melakukan aktivitas fisik.

\section{Hasil Penelitian Kualitatif}

\section{Evaluasi Formatif}

Evaluasi formatif dilakukan untuk menilai kelebihan dan kekurangan material dan strategi kampanye sebelum dan selama implementasi kampanye media SALAM Sehat. Evaluasi ini terdiri dari penilaian terhadap kelebihan dan kekurangan kampanye media SALAM Sehat serta saran dan masukan untuk keberlanjutan program kampanye media SALAM.

Menurut informan, kelebihan dari kampanye media SALAM Sehat yaitu memiliki media yang informatif, disebarkan secara berkala dengan pesan yang spesifik, sehingga lebih mudah diterima, mudah diingat, lebih sederhana, dan mudah dipahami.

A1: Kalau dari kami kampanye dengan poster seperti ini sudah bagus, jadi pesan yang disampaikan e mudah dicerna. Apalagi ini sudah menggunakan gambar-gambar jadi bisa.

Menurut informan, kekurangan kampanye media SALAM Sehat yaitu kebingungan organisasi mahasiswa ketika menyesuaikan penggunaan warna untuk desain dalam pembuatan media. Selain itu, masih terdapat poster yang membutuhkan informasi lebih detail agar diterima secara holistik serta masih ada poster yang dipenuhi tulisan, sehingga kurang nyaman saat dibaca. Selain itu, penyebaran media secara berkala ini yaitu membutuhkan usaha lebih dalam pembuatan media karena dibutuhkan banyak media. Di samping itu, ada kemungkinan penerimaan pesan oleh sasaran tidak komprehensif.

B6: ... Soalnya kan misal disebarkan lewat instagram atau lewat broadcast, satu per satu. Kalau saya pribadi, saya baca kesatu kedua udah stop saya nggak bakal baca lagi yang ketiga empat lima enam....

Menurut infroman, terdapat beberapa saran untuk program kampanye media SALAM Sehat yaitu:

a) Dibutuhkan kebijakan untuk mendukung program SALAM Sehat.

b) organisasi mahasiswa yang terlibat harus menjadi pelopor dalam menyadarkan perilaku SALAM Sehat.

c) Diperlukan fasilitas dan lingkungan yang mendukung perilaku SALAM Sehat.

d) Diperlukan kegiatan berupa acara yang mengenalkan SALAM Sehat, misalnya mengadakan launching untuk memperkenalkan SALAM Sehat, sosialisasi kampanye media SALAM Sehat melalui penampilan di kantin, dan lain-lain.

e) Ada sarana konseling dengan ahli di FKKMK untuk mengatasi masalah kesehatan mental.

f) Kerjasama dengan dosen dan tenaga kependidikan dalam menjalankan kampanye media SALAM Sehat.

g) Pemanfaatan TV dan monitor di lingkungan kampus FKKMK untuk pemutaran filler SALAM Sehat.

A1: kalau saran dari saya mungkin, dari advokasi temen-temen sudah cukup bagus, sudah sampai ranah dekan sudah cukup bagus. Untuk ke depan advokasinya untuk fasilitasnya, agar keinginan sudah ada tapi lingkungan tidak mendukung kan juga susah.

Beberapa masukan terkait keberlanjutan kampanye media SALAM Sehat menurut informan, antara lain:

a) Koordinasi dengan pemangku kepentingan seperti dvokasi ke setiap prodi untuk menyosialisasikan kampanye media SALAM Sehat agar menyeluruh di FKKMK.

b) Terdapat regenerasi tim SALAM Sehat melalui rekrutmen. 
c) Masing-masing organisasi mahasiswa dapat membuat program terkait kampanye media SALAM Sehat.

d) Kampanye direalisasikan melalui kegiatan seperti peregangan bersama sebelum perkuliahan.

e) Optimalisasi dan evaluasi pemasangan media di kampus.

f) Kampanye media SALAM Sehat disebarkan juga kepada masyarakat luas di luar kampus.

A5: Hehe. Kalau iya sih, tapi semisal kalau mau dilanjutkan mungkin regenerasi ya, kita rekruting baru untuk join.

\section{Evaluasi Proses}

Evaluasi proses mengukur usaha dan keluaran langsung dari kampanye media SALAM Sehat termasuk melihat proses dalam implementasi program. Evaluasi ini terdiri dari persepsi terkait kampanye media SALAM Sehat dan HPU, kesesuaian kampanye media SALAM Sehat dengan sasaran, media terbaik secara keseluruhan, pengorganisasian organisasi mahasiswa, penyebaran media, hambatan dan pendukung dalam melakukan kampanye media SALAM Sehat.

Menurut informan, HPU merupakan upaya untuk menjadikan kampus sebagai contoh penerapan gaya hidup sehat di tengah masyarakat dengan cara menjadikan kampus sebagai tempat yang ramah lingkungan, memiliki kantin sehat, kawasan bebas rokok, fasilitas beraktivitas fisik, layanan pemeriksaan kesehatan rutin, dan layanan konsultasi. Hal tersebut diharapkan dapat berlaku di tingkat universitas.

B5: Kalau saya pertama kali dengar Health Promoting University itu ya waktu ada acara seminar di Tahir Fondation yang dari Thailand itu.... pokoknya Health Promoting University itu gimana supaya kampus itu menjadi contoh buat masyarakat bisa menerapkan gaya hidup sehat seperti itu. Setahu saya itu.

Menurut informan, kampanye media SALAM Sehat merupakan program baru dan menarik yang berfokus pada upaya preventif dan telah disebarkan secara berkala melalui media sosial berdasarkan kerjasama antara mahasiswa sarjana dan pascasarjana yang diharapkan menghasilkan gerakan yang lebih besar. Program ini juga dinilai sejalan dengan Gerakan Masyarakat Hidup Sehat (Germas).

A5: ...Mungkin dari kerjasama dari S2 dan S1 ini itu apa ya, justru membuat gerakan yang lebih besar, menjangkau seluruh kalangan. Menurut saya ini apa ya, programnya sangat baru dan menarik sekali.

Menurut informan, kampanye media SALAM Sehat ini menjadi dasar, bagian, dan langkah serta mendukung penerapan HPU secara keseluruhan.

A6: Kalau dari saya pribadi sebagai mahasiswa S1 dan di zaman sekarang ini, promosi gini ini sangat baik, karena ya kegiatan kita sekarang itu lebih banyak ke arah e-learning gitu, apa-apa itu semuanya di media sosial. Jadi sangat mendukunglah Health Promoting University.

Menurut informan, kampanye media SALAM Sehat melalui online sesuai dari sisi konten poster yang memiliki pesan implisit dan singkat dilengkapi dengan caption untuk penjelasan. Selain itu, poster online tersebut dianggap lebih sesuai untuk meningkatkan kesadaran. Di samping itu, beberapa poster dirasa telah memiliki informasi yang cukup jelas. Di samping itu, media SALAM Sehat berisi pesan yang mendukung perilaku sehat di kampus seperti peregangan di tengah kesibukan mengerjakan tugas. Selain itu, konten media menarik dengan tulisan yang singkat dan dilengkapi gambar.

B5: Saya yang 6. Kita mahasiswa, jadi sering kan, keseharian dari jam pagi sampai malam depan laptop nggak berhenti-henti, kadang kan lupa, cuma sholat aja kan. Jadi untuk 
kita mahasiswa paling cocok ini kalau disuruh milih. Apalagi kita udah mulai tugas akhir segala macam, perlu peregangan. Kita kan kalau capek banget kayak gitu, sakit banget, merah, mata gue juga merah, perlu melihat yang hijau-hijau, gitu kan. Mungkin bisa dipasang di sekitar perpustakaan.

Menurut informan, media yang dianggap terbaik secara keseluruhan dalam kampanye media SALAM Sehat yaitu poster nomor 9 karena implisit dan dirasa efektif dalam peningkatan kesadaran, poster nomor 7 karena informatif, poster nomor 1 karena memuat informasi yang lengkap mengenai tiga perilaku dalam SALAM Sehat, poster nomor 6 karena mengandung pesan yang mudah diterima, lucu, dan sesuai dengan aktivitas mahasiswa, dan poster nomor 3 karena memiliki keseimbangan warna dan gambar serta mengandung informasi yang jelas dan detail.

A4: Saya nomor 1 ya. Kenapa? Karena itu lengkap, ada konsumsi buah sayur, aktivitas fisik. Saya sih nomor 1 karena ini lengkap mencakup semua.

Menurut informan, pengorganisasian organisasi mahasiswa dalam pembuatan media SALAM Sehat yakni salah satunya Himagika membentuk sebuah tim SALAM Sehat dengan pembagian tugas masing-masing seperti desain, konten, dan lain-lain.

A5: Yang buat media ini? Oh kalau di Himagika itu jadi kami membuat tim khusus untuk SALAM Sehat, jadi diharapkan, kenapa kok dibuat tim khusus itu karena mengingat kegiatan Himagika itu kan juga banyak e apa ya, biar tetap berjalan dan tetap ada yang menghandle makanya tim isinya itu bukan hanya dari pengurus Himagika saja tapi anggota juga. Nah itu, kami membuat apa ya, membuat pembagian tugas gitu, ada yang mendesain, ada yang bagian untuk, ada yang saya mendesain, terus teman-teman yang lain itu memberi saran untuk konten. Jadi nih desainnya seperti ini, saya lemparkan lagi ke tim itu, ada masukan apa nanti diperbaiki seperti itu.

Menurut informan, hambatan yang dirasakan dalam melakukan kampanye media SALAM Sehat antara lain disebabkan penyebaran media dilakukan melalui online, maka timbal balik minim dari sasaran dan media akan tertumpuk oleh informasi lain dalam waktu yang relatif singkat. Di samping itu, hambatan dalam pembuatan media yang dirasakan organisasi mahasiswa yaitu kesibukan masing-masing anggota tim yang mengharuskan bahasan media hanya melalui grup online. Selain itu, hanya satu orang yang mendesain media, sehingga sangat bergantung pada keluangan waktu petugas desain.

A6: Mau nambahin terkait promosinya di sosial media, selain karena nggak ditanggepin tadi, ini kan zamannya informasi, ketika kita ngeshare ini, lima menit kemudian informasi lain muncul gitu.

Menurut informan, pendukung yang dirasakan dalam melakukan kampanye media SALAM Sehat antara lain terdapat SOP yang disepakati dalam penyebaran media, kerjasama antara mahasiswa sarjana dan pascarjana yang dapat membuat gerakan lebih besar, dan media online ini sesuai dengan zaman media sosial sekarang ini.

A5: Jadi sewaktu-waktu, asalkan sudah, kalau dari kemarin itu kan sudah membuat apa sih namanya SOPnya, kita tinggal lihat timeline itu sih lihat waktunya untuk dishare.

Menurut informan, penyebaran media SALAM Sehat melalui akun dan grup media sosial organisasi kemudian anggota grup menyebarkan masing-masing ke grup lain yang dimiliki serta dilakukan pengulangan penyebaran media untuk meningkatkan kesadaran. Selain itu, penyebaran media juga diselaraskan dengan program kerja organisasi. Di samping itu, telah dilakukan sosialisasi media SALAM Sehat melalui Kongres Organisasi Mahasiswa FKKMK.

A2: Kalau kami IMP ini sudah sinergis dengan divisi kesehatan dan olahraga, itu setiap hari rabu itu ada menyampaikan info-info kesehatan.... 


\section{PEMBAHASAN}

\section{Gambaran Kesadaran Sasaran terhadap Kampanye Media SALAM Sehat}

Berdasarkan model Hierarchy Effect of Mass Media Campaign pada tujuan jangka pendek yaitu kesadaran dan paparan terhadap media kampanye yang diukur dengan melihat seberapa besar sasaran pernah melihat atau mendengar kampanye, mendengar tagline kampanye dan mengingat pesan kampanye. Pada kampanye media salam sehat ini menunjukkan bahwa sebagian besar responden 64,9\% menyatakan pernah melihat atau mendengar kampanye salam sehat, dengan topik yang paling sering dilihat adalah tentang SAntap buah dan sayur setiap hari yaitu sebesar 56,8\% dan pesan yang paling diingat adalah konsumsi buah dan sayur. Hal ini menunjukkan bahwa tingkat kesadaran terhadap kampanye mencapai level yang sedang (Evans-lacko, Luciano, \& Thornicroft (2016).

\section{Penilaian Konten Media SALAM Sehat}

Berdasarkan penilaian konten pesan kampanye, secara menyeluruh pesan kampanye media SALAM Sehat sudah memenuhi semua syarat elemen pesan dari Cutlip, Center \& Brown yaitu courtesy (kesesuaian isi dengan penerima pesan, untuk menunjukan perhatian pada penerima pesan), councreteness (kejelasan isi pesan sesuai dengan topik dari pesan yang akan disampaikan), completeness (pesan lengkap dan mengandung informasi yang mendukung), correctness (pesan terpercaya dan akurat), conciseness (pesan ringkas), clarity (pesan mudah untuk dipahami) dan consideration (pesan sesuai dengan situasi dan kondisi) yang berarti pesan yang disampaikan mudah untuk dipahami dan sesuai dengan kebutuhan dan kondisi responden (Mukarom \& Laksana, 2015 cit. Stellarosa \& Kurniasari, 2009). Hal ini sesuai dengan Bauman et al. (2006) yang menyebutkan bahwa kampanye media pada dasarnya bertujuan memberikan pengaruh untuk meningkatkan kesadaran dengan memberikan pemahaman tentang topik kampanye dan persepsi kesesuaian kampanye terhadap kondisi sasaran. Selain itu elemen pesan terkait keakuratan pesan, kemudahan pesan untuk dipahami, dan kesesuaian pesan pada penerima pesan menunjukkan kredibilitas pesan dan menilai dampak yang dirasakan terhadap kampanye (Vickers, 2015).

\section{Evaluasi Formatif Kampanye Media SALAM Sehat}

Menurut perwakilan mahasiswa dan organisasi mahasiswa dalam FGD menyebutkan bahwa Media SALAM Sehat yang sudah disebarkan secara online berupa poster dan filler memiliki kelebihan mudah dipahami dan informatif di mana media kampanye berbasis online ini sangat mudah untuk diperoleh dan disebarkan secara meluas, hal ini menunjukkan kampanye media SALAM Sehat melalui penyebaran online diterima dan sesuai dengan sasaran (Napolitano, Hayes, Bennett, Ives, \& Foster, 2013). Bauman et al., (2006) menyebutkan bahwa kampanye media yang efektif membutuhkan waktu dan sumber daya yang besar dalam mengembangkan isi pesan kampanye yang konsisten serta diperlukan 
keberlangsungan penyampaian pesan yang terus menerus agar pesan mampu mencapai sasaran. Di samping itu, diperlukan integrasi dengan kebijakan, pengadaan lingkungan, serta kerjasama yang lebih luas di mana adanya integrasi tersebut dapat meningkatkan capaian hasil yang lebih besar (Kite, Grunseit, et al., 2018). Selain itu, perlu dilakukan event tertentu agar kampanye media SALAM Sehat lebih diketahui oleh masyarakat luas (Kurniadi \& Hizasalasi, 2017).

\section{Evaluasi Proses Kampanye Media SALAM Sehat}

Kampanye ini berdasarkan kerjasama antara mahasiswa sarjana dan pascasarjana sehingga diharapkan menghasilkan gerakan yang lebih besar. Kampanye media melalui kerjasama dengan organisasi-organisasi yang keberadaan akun medianya telah diakui berguna untuk membangun komunitas online, bisa mendukung dan mempromosikan kampanye lebih luas (Freeman, Potente, Rock, \& Mciver, 2015). Kampanye media SALAM Sehat juga dinilai mendukung HPU di FKKMK UGM. Hal ini sesuai dengan kegiatan inisiasi Healthy University yaitu adanya produksi media berupa poster yang berisi informasi terkait isu kesehatan di mana produksi dan desain poster berasal dari komunitas mahasiswa sendiri (Knight \& Placa, 2013). Kampanye melalui media online dinilai efektif dalam meningkatkan kesadaran terhadap kampanye, dan menarik perhatian banyak sasaran serta merupakan suatu bentuk promosi kesehatan yang bertujuan untuk memberikan motivasi dalam melakukan kegiatan yang meningkatkan kesehatan dan mencegah kesakitan (Freeman et al., 2015; Mehri, Solhi, Garmaroudi, Nadrian, \& Sighaldeh, 2016).

Keterlibatan beberapa organisasi atau tim akan membuat program menyesuaikan dengan budaya dan lingkungan organisasi, sehingga disepakati Standar Operational Procedure dalam menjalankan Kampanye Media SALAM Sehat (Knight \& Placa, 2013). Selain itu, penyebaran media online melalui grup atau official account di setiap organisasi dinilai mudah disebarluaskan. Selain itu, didukung dengan adanya sosialisasi SALAM Sehat di event organisasi seperti Kongres Organisasi Mahasiswa BEM KM FKKMK dan Sarasehan IMP-IKM. Penyebaran kampanye secara ideal harus menyebar dari orang ke orang secara otomatis melalui proses berbagi halaman jaringan sosial yang ada (Freeman et al., 2015).

\section{KESIMPULAN}

Berikut kesimpulan dari evaluasi Kampanye Media SALAM Sehat di FKKMK UGM:

1. Sebagian besar responden memiliki kesadaran terhadap Kampanye Media SALAM Sehat sebagai inisiasi HPU di FKKMK UGM.

2. Pesan media SALAM Sehat dinilai telah memenuhi ketentuan elemen pesan.

3. Kampanye media SALAM sehat membutuhkan pengembangan pesan yang konsisten, terintegrasi dengan kebijakan, pengadaan lingkungan, serta kerjasama yang lebih luas. 
4. Kampanye media SALAM Sehat merupakan program inovatif yang melibatkan kerjasama antarorganisasi mahasiswa, namun terdapat kendala berupa koordinasi internal yang bergantung pada budaya organisasi.

\section{DAFTAR PUSTAKA}

Asian University Network-Health Promotion Network (AUN-HPN). (2017). AUN Healthy University Framework. ISBN: 978-616-443-047-1. AUN-Health Promotion Network, Mahidol University, Thailand.

Bauman, A., Smith, B. J., Maibach, E. W., \& Reger-Nash, B. (2006). Evaluation of mass media campaigns for physical activity. Evaluation and Program Planning, 29(3), 312-322. https://doi.org/10.1016/j.evalprogplan.2005.12.004.

Coffman, J. (2002). Lessons in Evaluating Communications Campaigns. Harvard Family Research Project, (June), 45.

Cresswell, J.W. (2016). Research Design: Pendekatan Metode Kualitatif, Kuantitatif, dan Campuran. Yogyakarta: Pustaka Pelajar.

Evans-lacko, S., Luciano, J. V , \& Thornicroft, G. (2016). Impact of the mass media OBERTAMENT campaign on the levels of stigma among the population of Catalonia, Spain. European Psychiatry, 31, 44-51.

Fertman, Carl \& Allenssworht, Diane. (2010). Health Promotion Programs From Theory to Practice. San Francisco : Jossey-Bass.

Freeman, B., Potente, S., Rock, V., \& Mciver, J. (2015). Social media campaigns that make a difference: what can public health learn from the corporate sector and other social change marketers ?, 25(March), 1-8.

Kementerian Kesehatan Republik Indonesia. (2016). Laporan Survei Indikator Kesehatan Nasional (Sirkesnas) 2016, (17).

Kite, J., Gale, J., Grunseit, A., Bellew, W., Li, V., Lloyd, B., ... Bauman, A. (2018). Impact of the Make Healthy Normal mass media campaign (Phase

1) on knowledge, attitudes and behaviours: a cohort study. Australian and New Zealand Journal of Public Health, (Phase 1), 1-8. https://doi.org/10.1111/1753-6405.12779

Kite, J., Grunseit, A., Bohn-goldbaum, E., Bellew, B., Carroll, T., Kite, J., ... Carroll, T. O. M. (2018). A Systematic Search and Review of AdultTargeted Overweight and Obesity Prevention Mass Media Campaigns and Their Evaluation : 2000 - 2017 A Systematic Search and Review of AdultTargeted Overweight and Obesity Prevention Mass Media Campaigns and Their Ev. Journal of Health Communication, 23(2), 207-232. https://doi.org/10.1080/10810730.2018.1423651

Knight, A., \& Placa, V. La. (2013). International Journal of Health Healthy Universities : taking the University of Greenwich Healthy Universities Initiative forward, (February), 37-41.

Kurniadi, H., \& Hizasalasi, M. (2017). Strategi Komunikasi Dalam Kampanye Diet Kantong Plastik Oleh Gidkp Di Indonesia. Jurnal Ilmiah Fakultas Ilmu Komunikasi Universitas Islam Riau, 6. 
Mehri, A., Solhi, M., Garmaroudi, G., Nadrian, H., \& Sighaldeh, S. S. (2016). Health promoting lifestyle and its determinants among university students in Sabzevar, Iran. International Journal of Preventive Medicine, 2016April, 1-11. https://doi.org/10.4103/2008-7802.180411

Napolitano, M. A., Hayes, S., Bennett, G. G., Ives, A. K., \& Foster, G. D. (2013). Using Facebook and Text Messaging to Deliver a Weight Loss Program to College Students, 21(1), 25-31. https://doi.org/10.1038/oby.2012.107.

Potter, Sharyn., Moynihan, Mary., Stapleton, Jane, et al., (2009). Empowering Bystanders to Prevent Campus Violence Against Women A Preliminary Evaluation of a Poster Campaign. Violence Against Women Volume 15 Number 1 January 2009 106-121.

Ramadhan, Muhammad., (2017). Perancangan Media Komunikasi Visual Pada Kampanye Sosial Donor Darah. e-Proceeding of Art \& Design : Vol.4, No.3 Desember 2017.

Saryono \& Anggraeni M.D. (2011). Metodologi Penelitian Kualitatif dalam Bidang Kesehatan. Yogyakarta: Nuha Medika.

Soh, Chin Thing. (2015). Smoke-Free Campus Policy And Smoking Behavior Comparison Of 2003 and 2007 FM UGM Student Survey. Yogyakarta : Universitas Gadjah Mada

Stellarosa, Y., \& Kurniasari, M. (2009). Pengaruh Pesan Kampanye Diet Sehat: Latar Belakang Masalah, 371-387.

Vickers, N. (2015). 2015 National Tobacco Campaign Research Evaluation Final Report. Department of Health - 2015 National Tobacco Campaign Evaluation, (September).

World Health Organization. (2012). A Comprehensive Global Monitoring Framework Including Indicators And A Set Of Voluntary Global Targets For The Prevention And Control Of Noncommunicabale Diseases Introduction, (September 2011), 1-23. Retrieved from http://www.who.int/nmh/events/2012/discussion_paper2_20120322. Pdf.

World Health Organization. (2017). Noncommunicable Diseases Progress monitor 2017. 